\title{
EFEITOS DA SOLARIZAÇÃO DO SOLO ATRAVÉS DE PLÁSTICO TRANSPARENTE SOBRE O DESENVOLVIMENTO DA TIRIRICA (Cyperus rotundus) ${ }^{1}$
}

\author{
MARCOS A. KUVA ${ }^{2}$, PEDRO L.C.A. ALVES ${ }^{3}$ e EDUARDO L.A. ERASMO ${ }^{4}$
}

RESUMO

\begin{abstract}
Um ensaio foi conduzido em condições de campo, durante o verão, com o objetivo de avaliar o potencial da técnica de solarização do solo no controle da tiririca (Cyperus rotundus $L$.). O delineamento experimental utilizado foi o de blocos casualizados com três repetições, e os tratamentos num esquema fatorial $2 \times 2 \times 3$, sendo duas situações de cobertura (com e sem plástico transparente de $300 \mu \mathrm{m}$ de espessura), dois estádios de desenvolvimento da planta daninha (vegetativo e florescimento) e três períodos de cobertura com plástico (15, 30 e 60 dias). A temperatura do solo sob solarização teve um aumento médio de $4,3^{\circ} \mathrm{C}$ em relação à testemunha, atingindo valores superiores a $50^{\circ} \mathrm{C}$ em determi
\end{abstract}

nados horários. Observou-se, também, um acúmulo da ordem de $400 \%$ nos teores de $\mathrm{CO}_{2}$ na atmosfera do solo solarizado. Nessas condições houve inibição da brotação dos tubérculos e diminuição no peso de matéria seca de todas as partes estudadas da planta. Houve redução na taxa de multiplicação dos tubérculos, reduzindo-a de 1:11 para 1:4, quando coberta no estádio vegetativo e para 1:9 quando a cobertura se realizou no estádio de florescimento. Houve, ainda, diminuição na ordem de $20 \%$ na viabilidade dos tubérculos remanescentes.

Palavras-chave: Plantas daninhas, controle físico, temperatura, biologia, estratégia reprodutiva.

\section{ABSTRACT \\ The effects of soil solarization with transparent plastic on purple nutsedge (Cyperus rotundus)}

The research was conducted under field conditions during the summer period, to evaluate the solarization effect on purple nutsedge (Cyperus rotundus) control. The experimental design was randomized blocks with three replications. The treatments were arranged in a factorial scheme $2 \mathrm{X}$ $2 \times 3$, with two cover conditions (with and without transparent plastic sheet, $300 \mu \mathrm{m}$ thickness), two periods of covering (vegetative and flower stages), and three cover periods (15, 30 and 60 days). The soil temperature under solarization was $4.3^{\circ} \mathrm{C}$ higher than the control, reaching more than $50^{\circ} \mathrm{C}$ at certain times of day. An increase of $400 \%$ was observed in the $\mathrm{CO}_{2}$ concentration in the atmosphere of solarized soil. Under these conditions the tuber sprouting was inhibited and the dry weight of all parts of the plant was decreased. The rate of tuber multiplication was decreased from 1:11 to $1: 4$ when the plant was covered at the vegetative stage, and to 1:9 when it was covered at the reproductive stage. A decrease of $20 \%$ in tuber viability was also observed.

Additional index words: Weeds, physical control, temperature, biology, reprodutive strategics.

1 Recebido para publicação em 17/10/'94 e na forma revisada em 31/05/95.

2 Estagiário de Aperfeiçoamento, DBAA-FCAVJ-UNESP, Jaboticabal, SP 14870000

3 Professor Assistente, DBAA-FCAVJ-UNESP, Jaboticabal, SP 14870000

4 Pós-graduando, FCAVJ/UNESP, Jaboticabal, SP 14870000 


\section{INTRODUÇÃO}

Dentre os métodos físicos de controle das plantas daninhas, a solarização é uma das técnicas que têm sido mais desenvolvida entre os pesquisadores do mundo todo. Em síntese, a solarização consiste na desinfecção térmica das camadas superficiais do solo, elevando a temperatura, e assim limitando o desenvolvimento de patógenos, e provocando a morte de órgãos reprodutivos (sementes, rizomas bulbos e tubérculos) e de plântulas de espécies de plantas daninhas, através da cobertura do solo com plástico transparente durante o período mais quente do ano (Horowitz et al., 1983; Katan, 1981; Rubin \& Benjamin, 1983).

O aquecimento do solo ocorre devido ao impedimento, pela lâmina plástica, da emissão dos comprimentos de onda longos absorvidos e da evaporação da água, modificando assim o fluxo térmico entre a superficie do solo e a atmosfera (Katan, 1981). Além do efeito térmico, a cobertura apresenta outros efeitos que podem ser importantes quando se trata do controle das plantas daninhas. A própria barreira física que o plástico representa, alterações na atmosfera do solo quanto ao balanço entre $\mathrm{CO}_{2}$ e $\mathrm{O}_{2}$ (Egley \& Duke, 1965; Grant Lipp \& Ballard, 1959; Horowitz et al., 1983; Rubin \& Benjamin, 1984) e quanto a manutenção de compostos voláteis sob a cobertura (Egley \& Duke, 1965; Holm, 1972; Rubin \& Benjamin, 1983; Taylorson, 1979) que podem afetar a germinação de sementes.

A grande variabilidade obtida nos estudos dessa técnica pode ser explicada pelos inúmeros fatores que a afetam. Assim, o sucesso dependerá do tipo de cobertura, período e época de cobertura, umidade e textura do solo, profundidade do dissemínulo no solo e principalmente da espécie de planta daninha.

Verifica-se um maior poder de aquecimento do plástico transparente em relação ao preto (Horowitz et al., 1979; Katan, 1981; Liakatas, 1986, Rubin \& Benjamin, 1983, Stivens et al., 1990) pois o mesmo permite a ocorrência do efeito estufa (Katan, 1981; Liakatas, 1986). Quando a cobertura é realizada no período mais quente do ano existe uma eficiência maior com relação a mortalidade de diásporos e plântulas (Rubin \& Benjamin, 1983).

A cobertura do solo associada a alta umidade do solo, potencializa os efeitos da solarização, pois aumenta a condutividade térmica do solo, permitindo o aquecimento das camadas mais profundas (Horowitz et al., 1983; Jacobsohn et al., 1980) e aumenta a sensibilidade das sementes à altas temperaturas (Horowitz et al., 1983; Katan, 1981).

Com relação as diferentes espécies de plantas daninhas, a variação da eficiência deste método depende tanto da forma de reprodução e hábito de desenvolvimento da mesma, como do estádio em que se encontra na ocasião da cobertura. A solarização tem sido utilizada com sucesso no controle de plantas daninhas parasitas (Abu-Irmaileh, 1992; Braum et al., 1988; Jacobsohn et al., 1980) e da maioria das plantas daninhas anuais, cuja reprodução se realiza por sementes (Al-Masoom et al., 1993; Cardoso, 1989; Egley, 1993; Horowitz et al., 1983; Rubin \& Benjamin, 1984; Standifer et $a L, 1984)$. Quanto às plantas daninhas que se reproduzem vegetativamente, como é o caso da tiririca, essa mesma eficiência não tem se repetido (Braun et aL, 1988;
Cardoso, 1989; Egley, 1993; Rubin \& Benjamin, 1983; Rubin \& Benjamin, 1984), sendo requeridas, portanto, maiores informações sobre o desenvolvimento dessas espécies sob condições de solarização.

A tiririca (Cyperus rotundus) devido a sua ampla distribuição geográfica e principalmente pelo eficiente sistema reprodutivo que apresenta, tem-se mostrado bastante resistente a qualquer método de controle que seja aplicado isoladamente, sendo necessário um programa de manejo, no qual, todo e qualquer método merece ser investigado.

O presente trabalho teve como objetivo avaliar o efeito do uso de cobertura plástica transparente durante o verão, sobre o microclima do solo e sob o desenvolvimento da tiririca e, além disso, avaliar qual é o estádio de desenvolvimento da planta mais suscetível à solarização e o período de cobertura do solo para a maximização dos seus efeitos.

\section{MATERIAL E MÉTODOS}

O ensaio foi conduzido em condições de campo, durante o período de novembro de 1992 a março de $1993 \mathrm{em}$ área experimental pertencente ao Departamento de Biologia Aplicada à Agropecuária (FCAV, UNESP, Campus Jaboticabal) sobre Latossolo Vermelho-Escuro, Distrófico, A Moderado.

O delineamento experimental utilizado foi o de blocos casualizados com três repetições e os tratamentos num esquema fatorial $2 \times 2 \times 3$, conforme descrição na Tabela 1 .

TABELA 1 - Condiçōes de cobertura, estádio de desenvolvimento da planta e períodos de cobertura que constituíram os tratamentos experimentais. Jaboticabal (SP), 1992.

\begin{tabular}{c|lc}
\hline Cobertura & Estádio da planta & $\begin{array}{c}\text { Período de } \\
\text { cobertura (dias) }\end{array}$ \\
\hline Presente & Vegetativo & 15 \\
Presente & Vegetativo & 30 \\
Presente & Vegetativo & 60 \\
Presente & Florescimento & 15 \\
Presente & Florescimento & 30 \\
Presente & Florescimento & 60 \\
Ausente & Vegetativo & 15 \\
Ausente & Vegetativo & 30 \\
Ausente & Vegetativo & 60 \\
Ausente & Florescimento & 15 \\
Ausente & Florescimento & 30 \\
Ausente & Florescimento & 60 \\
\hline
\end{tabular}

Como estádio vegetativo, considerou-se plantas com trinta dias após o plantio e, o estádio de florescimento, quando aproximadamente $70 \%$ das manifestações epígeas estavam com inflorescência. 
Para que a cobertura do solo com plástico fosse realizada no mesmo dia, porém com a tiririca em dois estádios de desenvolvimento, o plantio da tiririca nas parcelas referentes ao estádio vegetativo foi defasado em 15 dias em relação às parcelas cuja cobertura se realizou no estádio de florescimento.

As parcelas experimentais constituíram-se de caixas de armação de ferro $(50 \mathrm{~cm} \times 50 \mathrm{~cm} \times 30 \mathrm{~cm})$ revestidas com tela de poliolefina (sombrite). As mesmas foram enterradas no solo obedecendo um espaçamento de $2 \mathrm{~m} \times 2 \mathrm{~m}$ e preenchidas com terra peneirada até o nível do solo, recebendo, cada uma, quatro tubérculos previamente brotados. Estes tubérculos foram marcados com fios plásticos coloridos.

Em cada caixa foram colocados três dispositivos de coleta de ar (pedra porosa conectada a um tubo de polietileno que saia da superfície do solo) a três diferentes profundidades $(5,10$ e $20 \mathrm{~cm})$.

Quando as populações atingiram os estádios desejados (vegetativo e florescimento) as parcelas foram cobertas com plástico transparente de $300 \mu \mathrm{m}$ de espessura. Ao final de cada período de cobertura $(15,30$ e 60 dias), retirou-se o plástico e as parcelas permaneceram no campo por mais 30 dias após o respectivo período de cobertura, quando, então, as parcelas foram retiradas e analisadas.

Durante todo o período experimental monitorou-se o comportamento de alguns elementos ambientais internos (sob a cobertura). Diariamente foram medidas a temperatura do solo a três diferentes profundidades $(5,10$ e $20 \mathrm{~cm})$, utilizando-se termômetros de solo, com medições às 9:00 h; 13:00 h e 17:00 h. Durante as duas primeiras semanas após a cobertura, acompanhou-se, também, o comportamento diário da concentração de $\mathrm{CO}_{2}$ na atmosfera do solo, utilizando-se o método potenciométrico descrito por Zunker \& Kreeb, 1970.

Elementos ambientais externos, sobre a cobertura, também foram monitorados diariamente. Dados de temperatura média, mínima e máxima, umidade relativa do ar, precipitação pluviométrica e insolação, foram obtidos na Estação Agroclimática do Departamento de Ciências Exatas da FCAV-UNESP/Campus Jaboticabal (lat: $21^{\circ} 15^{\prime} 22^{\prime \prime}$ S; long: $48^{\circ} 18^{\prime} 58^{\prime \prime} \mathrm{W}$; alt: $595 \mathrm{~m}$ ).

Decorridos 30 dias após a retirada da cobertura, foi feita contagem de manifestações epígeas verdes. Em segui$\mathrm{da}$, as parcelas foram desmontadas, sendo a tiririca separada em suas diferentes partes (parte aérea, tubérculos + bulbos, rizomas e raízes) para obtenção da biomassa seca.

$\mathrm{O}$ número de tubérculos total e parcial (primário, secundário, terciário e quaternário) também foram avaliados procurando-se determinar um modelo de multiplicação decorrente de cada tratamento, em função do tubérculo inicialmente posto para se desenvolver (marcado).

Aos tubérculos aparentemente vivos aplicou-se o teste topográfico do tetrazólio a fim de se determinar a viabilidade dos mesmos nos diferentes tratamentos.

Os dados obtidos foram submetidos à análise de variância pelo test $\mathrm{F}$ desdobrando-se, no fatorial, os efeitos dos fatores principais e suas interações. Quando o efeito principal ou alguma interação foi significativa foi aplicado o teste de Tukey a 5\% de probabilidade para comparação das médias.

\section{RESULTADOS E DISCUSSÃO}

Elementos Ambientais

Durante o período experimental, a temperatura média do ar variou em torno de $23,6^{\circ} \mathrm{C}$, atingindo um mínimo de $17,7^{\circ} \mathrm{C}$ e um máximo de $29,7^{\circ} \mathrm{C}$. A umidade relativa do ar manteve-se em média a 77,4\%, registrando um acúmulo de 1023,9 mm de precipitação pluviométrica e 732,5 h de insolação.

A cobertura plástica promoveu aumento na temperatura do solo, em todo o seu perfil. Observou-se que as maiores temperaturas foram atingidas às 17:00 $\mathrm{h}$, independente da profundidade considerada. As temperaturas foram, em média, $37,7^{\circ} \mathrm{C}, 38,6^{\circ} \mathrm{C}$ e $35,3^{\circ} \mathrm{C}$ a 5,10 e $20 \mathrm{~cm}$ de profundidade, respectivamente (Figura 1). Horowitz et al. (1979) observaram que que a temperatura do solo atingiu $45,5^{\circ} \mathrm{C}$ e $40,3^{\circ} \mathrm{C}$ nas profundidades de 5 e $15 \mathrm{~cm}$, respectivamente, abaixo da cobertura plástica. Egley (1993), medindo a temperatura do solo solarizado ( $5 \mathrm{~cm}$ de profundidade) entre $15 \mathrm{e}$ 16 horas observou uma temperatura máxima de $60^{\circ} \mathrm{C}$, sendo, em média $10^{\circ} \mathrm{C}$ superior à temperatura verificada no solo nú.

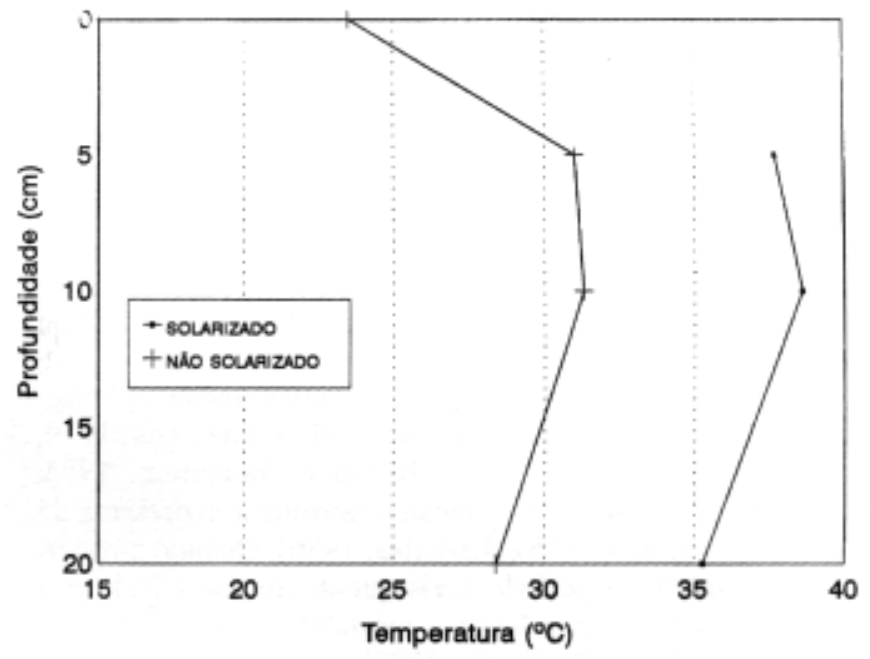

FIG. 1 - Variaçāo térmica no perfil do solo sob cobertura plástica transparente ( - solarizado) e sem cobertura (+ nẩo solarizado).

A exemplo do que indicam os estudos realizados por Horowitz et al.(1983) e Rubin \& Benjamin (1984), constatou se que a solarização favoreceu o acúmulo de $\mathrm{CO}_{2}$ em todo perfil estudado, acarretando num aumen to médio de $400 \%$ em sua concentração (Figura 2).

\section{Planta Daninha}

O solo utilizado apresentava-se bastante acidificado $\left(\mathrm{pH}\right.$ em $\left.\mathrm{CaCl}_{2}=3,9\right)$ e com baixa saturação por bases $(\mathrm{V} \%=$ 14). Segundo Durigan (1991) a emissão de manifestações epígeas é limitada pelas condições de baixa fertilidade do solo. Deve-se, portanto, frisar a particularidade dos resultados obtidos.

A solarização do solo infestado por tiririca, independente do estádio de desenvolvimento da planta em que é feita 


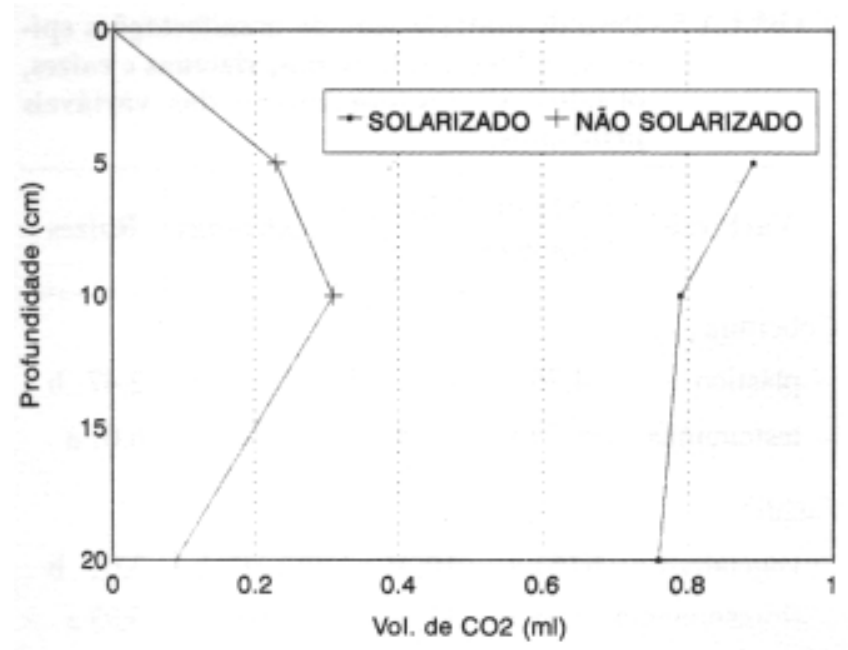

FIG. 2 - Variação percentual da concentração de $\mathrm{CO}_{2}$ no perfil do solo sob cobertura plástica transparente (*-solarizado) e sem cobertura (+ náo solarizado).

a cobertura e do período em que se mantém a parcela coberta reduziu o número de manifestações epígeas da planta daninha (Tabela 2).

Quando se analisou os fatores estádio e período isoladamente, observou-se que a parcelas referentes ao estádio vegetativo apresentaram menor número de manifestações epígeas do que aquelas referentes ao estádio de florescimento, independente da cobertura ou não da parcela. Quanto

TABELA 2 - Número médio de manifestaçōes epígeas e tubérculos e porcentagem de tubérculos viáveis de tiririca, obtidos no desdobramento das variáveis principais.

\begin{tabular}{l|c|c|c}
\hline \multirow{2}{*}{ Variáveis } & \multicolumn{2}{|c|}{ Número $^{1}$} & \multirow{2}{*}{ Viabilidade $^{2}$} \\
& $\begin{array}{c}\text { Manif. } \\
\text { Epígeas }\end{array}$ & Tubérculos & \\
\cline { 2 - 3 } & \multicolumn{3}{|c}{} \\
\hline $\begin{array}{l}\text { Cobertura } \\
\text { plástico } \\
\text { testemunha }\end{array}$ & $3,19 \mathrm{~b}^{3}$ & $3,99 \mathrm{~b}$ & $60,75 \mathrm{~b}$ \\
Estágio & $5,89 \mathrm{a}$ & $5,25 \mathrm{a}$ & $75,44 \mathrm{a}$ \\
$\quad$ & & \\
vegetativo & $3,96 \mathrm{~b}$ & $5,55 \mathrm{a}$ & $63,87 \mathrm{a}$ \\
florescimento & $5,12 \mathrm{a}$ & $6,69 \mathrm{a}$ & $72,32 \mathrm{a}$ \\
Período & & & \\
15 dias & $4,95 \mathrm{a}$ & $5,90 \mathrm{a}$ & $86,64 \mathrm{a}$ \\
30 dias & $5,43 \mathrm{a}$ & $6,68 \mathrm{a}$ & $68,60 \mathrm{ab}$ \\
60 dias & $3,24 \mathrm{~b}$ & $5,78 \mathrm{a}$ & $49,05 \mathrm{~b}$ \\
\hline
\end{tabular}

${ }^{1}$ dados transformados para $\sqrt{\mathbf{x}}$.

2 dados transformados para arc sen $\sqrt{\%}$.

${ }^{3}$ médias seguidas de mesma letra năo diferem entre si pelo teste de Tukey ao nível de $5 \%$ de probabilidade. ao período, parcelas correspondentes a 60 dias apresentaram menor número de manifestações epígeas (Tabela 2).

Com relação ao número de tubérculos, observou-se que a solarização por um período de 15 dias já reduziu a multiplicação da planta daninha, sem, contudo, haver diferença entre os períodos de solarização e sem ser dependente do estádio de desenvolvimento da planta (Tabela 3 ).

TABELA 3 - Número ${ }^{1}$ de tubérculos obtidos no desdobramento da interaçáo entre a cobertura $e$ o período de cobertura

\begin{tabular}{l|c|c|c}
\hline \multirow{2}{*}{ Cobertura } & \multicolumn{3}{|c}{ Período de Cobertura } \\
\cline { 2 - 4 } & $\mathbf{1 5}$ dias & 30 dias & 60 dias \\
\hline plástico & s $4,56 \mathrm{a}^{2}$ & s 4,94 a & s 2,47 a \\
testemunha & r 7,24 a & r 8,41 a & r 9,09 a \\
\hline
\end{tabular}

Dados transformados para $\sqrt{\mathbf{x}}$.

'Médias seguidas de mesma letra năo diferem entre si pelo teste de Tukey ao nível de $5 \%$ de probabilidade, sendo que:

letras à esquerda $e$ no sentido da coluna, comparam a solarizaçăo à testemunha e,

letras à direita e no sentido da linha, comparam os diferentes períodos de cobertura.

Ao analisar a viabilidade dos tubérculos remanescentes, verificou-se que apenas a solarização por 60 dias causou redução significativa neste parâmetro, independente do estádio em que foi realizado (Tabela 4).

TABELA 4 - Porcentagem $^{1}$ de tubérculos viáveis obtidos no desdobramento da interaçäo entre a cobertura e o período de cobertura.

\begin{tabular}{l|c|c|c}
\hline \multirow{2}{*}{ Cobertura } & \multicolumn{3}{|c}{ Período de Cobertura } \\
\cline { 2 - 4 } & 15 dias & 30 dias & 60 dias \\
\hline plástico & r $87,85 \mathrm{a}^{2}$ & r 64,41 a & s 30,00 b \\
testemunha & r 85,44 a & r 72,78 a & r 68,10 a \\
\hline
\end{tabular}

${ }^{1}$ Dados transformados para are sen $\sqrt{\%}$.

${ }^{2}$ Médias seguidas de mesma letra náo diferem entre si pelo teste de Tukey ao nível de $5 \%$ de probabilidade, sendo que:

letras à esquerda e no sentido da coluna, comparam a solarizaçăo à testemunha e,

letras à direita e no sentido da linha, comparam os diferentes períodos de cobertura.

Rubin \& Benjamin (1984), utilizando a técnica de solarização obtiveram controle parcial da tiririca, sendo que o efeito inibitório foi um retardamento à reinfestação. $\mathrm{O}$ mesmo não ocorreu nos estudos realizados por Braun et al. (1988) que não obtiveram qualquer efeito sobre esta planta daninha.

Trabalhando-se com coeficientes médios que governaram a multiplicação dos tubérculos a partir do tubérculo inicialmente posto para se desenvolver, observou-se que a solarização, quando realizada no estádio vegetativo da planta daninha, independente da sua duração, reduziu drasticamente a multiplicação de tubérculos. Na testemunha um tubércu- 
lo marcado originou dois primários (1:2), e nas solarizadas a multiplicação foi de 1:1 e 1:2 para a cobertura no estádio vegetativo e florescimento, respectivamente. Mas, a partir dos tubérculos secundários já se observou efeito da solarização quando realizada no estádio de florescimento da planta, quando esta reduziu a proporção de multiplicação de 1:4 para 1:3. Para o estádio vegetativo o efeito da solarização foi mais acentuado, reduzindo a proporção para 1:1. Mesmos efeitos foram observados para os tubérculos terciários. Quanto à formação de tubérculos quaternários não se observou diferença do efeito da solarização quando esta foi realizada no estádio vegetativo ou de florescimento, quando para ambos os estádios a proporção foi de 1:1, enquanto que na testemunha foi de 1:2. De maneira global, um tubérculo posto para se desenvolver em parcela não solarizada originou 11 novos tubérculos num período total de 90 dias, enquanto que na parcela solarizada no estádio vegetativo esta multiplicação foi de 1:4 e, no estádio de flores cimento, foi de 1:9 (Figu ra 3). Magalhães (1965), estudando a tiririca em condições consideradas favoráveis, obteve uma multiplicação intensa à razão de 1:11 tubérculos em apenas 60 dias de desenvolvimento.
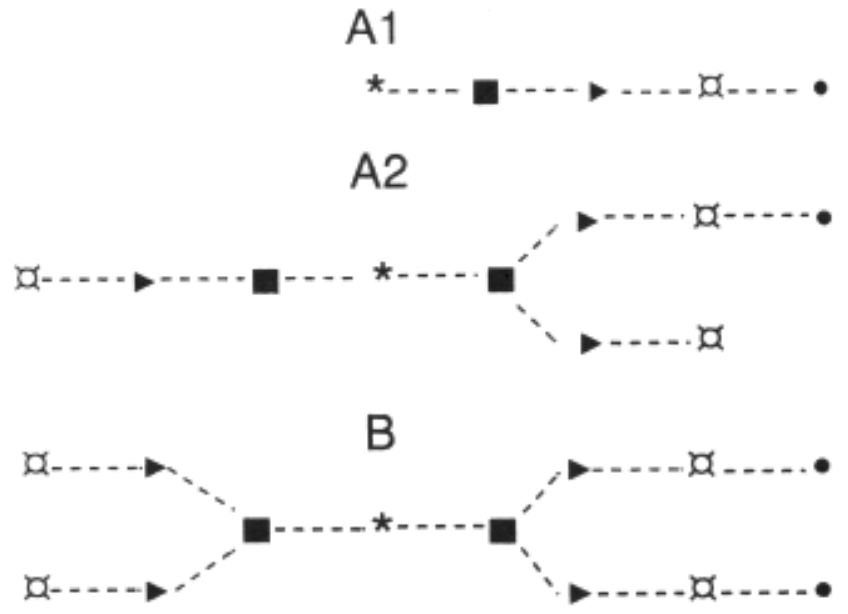

FIG. 3 - Representaçăo esquemática da tuberização da tiririca quando submetida à cobertura plástica transparente (solarização) no seu estádio vegetativo (A1) ou de florescimento (A2), em comparaçáo com a testemunha sem cobertura (não solarizada) (B). Sendo: ${ }^{*}=$ tubérculo inicial, D = primário, $\nabla$ = secundário, $\square=$ terciário, • = quaternário.

Tomando como parâmetro o peso de matéria seca, observou-se que a solarização causou redução em todas as partes estudadas da planta de tiririca, independente do período de cobertura e do estádio em que se encontrava a planta (Tabela 5).

Analisando isoladamente o estádio, plantas que estavam vegetando apresentaram menor peso de matéria seca de rizomas e raízes. Quanto ao período, observou-se que parcelas referentes ao período de 60 dias apresentaram menor peso de matéria seca de manifestações epígeas e de raízes (Tabela 5), o que pode ser atribuido à intensificação da interferên-
TABELA 5 - Peso de matéria seca de manifestaçôes epígeas, bulbos + tubérculos, rizomas e raízes, obtidos no desdobramento das variáveis principais.

\begin{tabular}{|c|c|c|c|c|}
\hline Variáveis & $\begin{array}{l}\text { Manif. } \\
\text { Epígeas }\end{array}$ & $\begin{array}{c}\text { Bulb. + } \\
\text { Tub. }\end{array}$ & Rizomas & Raízes \\
\hline \multicolumn{5}{|l|}{ Cobertura } \\
\hline plástico & $4,76 b^{1}$ & $5,20 \quad b$ & $0,87 \quad b$ & $2,47 \quad b$ \\
\hline testemunha & 18,79 a & 19,01 a & $2,51 \mathrm{a}$ & 6,07 a \\
\hline \multicolumn{5}{|l|}{ Estádio } \\
\hline vegetativo & 10,61 a & 10,41 a & $1,30 \quad b$ & $3,61 \quad b$ \\
\hline florescimento & 12,93 a & $13,80 \mathrm{a}$ & 2,08 a & 4,93 a \\
\hline \multicolumn{5}{|l|}{ Período } \\
\hline 15 dias & $16,36 \mathrm{a}$ & 9,71 a & 1,46 a & 5,44 a \\
\hline 30 dias & 15,68 a & 12,25 a & $2,08 \mathrm{a}$ & 5,17 a \\
\hline 60 dias & $3,27 \mathrm{~b}$ & 14,29 a & 1,54 a & $2,20 \quad b$ \\
\hline
\end{tabular}
${ }^{1}$ Médias seguidas de mesma letra não diferem entre si pelo teste de Tukey
ao nivel de $5 \%$ de probabilidade.

cia intraespecífica, aumentando a senescência de folhas e morte de raízes.

A redução no peso da matéria seca das raízes ocorreu quando a solarização foi realizada tanto no estádio vegetativo como no florescimento, sendo o efeito mais acentuado quando a planta foi coberta no estádio vegetativo (Tabela 6).

$\mathrm{O}$ peso de matéria seca da parte aérea (manifestações epígeas) foi reduzido pela solarização quando esta ocorreu por um período de 15 e 30 dias. Aos 60 dias já não se observou o efeito da solarização, uma vez que mesmo as plantas da testemunha apresentaram redução no peso da matéria seca da parte aérea (Tabela 7).

Pelos resultados obtidos pode-se inferir que a solarização durante o verão se mostrou um método promissor de controle, principalmente quando a planta é coberta no estádio vegetativo e por um período superior a 30 dias.

TABELA 6 - Peso de matéria seca de raízes obtido no desdobramentoda interaçáo entre cobertura e estádio de cobertura.

\begin{tabular}{l|c|c}
\hline \multirow{2}{*}{ Cobertura } & \multicolumn{2}{|c}{ Estádio de Desenvolvimento } \\
\cline { 2 - 3 } & Vegetativo & Florescimento \\
\hline Plástico & s $0,97 \quad \mathbf{b}^{1}$ & s 3,96 a \\
Testemunha & r 6,25 a & r 5,90 a \\
\hline
\end{tabular}

\footnotetext{
${ }^{1}$ Médias seguidas de mesma letra náo diferem entre si pelo teste de Tukey ao nível de $5 \%$ de probabilidade, sendo que:

letras à esquerda e no sentido da coluna, comparam a solarização à testemunha $\mathrm{c}$,

letras à direita e no sentido da linha comparam os diferentes estádios de desenvolvimento.
} 
TABELA 7 - Peso de matéria seca da parte aérea obtido no desdobramento da interação entre cobertura e período de cobertura.

\begin{tabular}{l|c|c|c}
\hline \multirow{2}{*}{ Cobertura } & \multicolumn{3}{|c}{ Período de Cobertura } \\
\cline { 2 - 4 } & 15 dias & 30 dias & 60 dias \\
\hline Plástico & s $7,15 \mathrm{a}^{1}$ & s 5,02 a & r 2,09 a \\
Testemunha & r 25,58 a & r 26,34 a & r 4,45 b \\
\hline
\end{tabular}

${ }^{1}$ Médias seguidas de mesma letra năo diferem entre si pelo teste de Tukey ao nível de $5 \%$ de probabilidade, sendo que:

letras à esquerda e no sentido da coluna, comparam a solarizaçăo à testemunha e,

letras à direita $\mathrm{c}$ no sentido da linha comparam os diferentes periodos de cobertura.

\section{AGRADECIMENTOS}

Ao Prof. Dr. Robinson Antonio Pitelli (UNESP/ FCAV, Jaboticabal, SP) e ao Prof. Dr. Julio César Durigan (UNESP/FCAV, Jaboticabal, SP) pelas importantes sugestões.

\section{LITERATURA CITADA}

ABU-IRMAILEH, B.E. Soil solarization controls broom rapes (Orobanche spp) in host vegetable crops in the Jordan Valley. Weed Technology, Champaign, v. 5, n. 3, p. 575-581, 1991. Apud Weed Abstracts, England, v. 41, n. 7, p. 310, 1992.

AL-MASOOM, A.A., SAGHIR, A., ITANI, S. Soil solarization for weed management in VAR Weed Technology, Champaign, v. 7, p. 507-510,1993.

BRAUN, M., KOCH, W., MUSSA, H.H., STIEFUATER, M. Solarization for weed and pest control possibilities and limitations In: CAVALLORO, R. EL TIK (ed). Weed control in vegetable production. Rotterdan: A.A. Balkema, 1988.

CARDOSO, A.A. Avaliação do efeito de solarização com filme plástico preto no controle de plantas daninhas. Jaboticabal: FCAV-UNESP, 1989. 36p. Trabalho de Graduação em Agronomia.

DURIGAN, J.C. Manejo da tiririca (Cyperus roáundus L.) antes e durante a implantação da cultura da canade-açucar (Saccharum spp). Jaboticabal: FCAVUNESP, 1991. 336 p. Tese de Livre Docência.

EGLEY, G.H. Weed seed and seedling reductions by soil solarization with transparent polyethylene sheets. Weed Science, Champaign, v. 31, p. 404-409, 1993.

EGLEY, G.H.; DUKE, E.O. Physiology of weed seed dormancy and germination.. In: DUKE, S.O. (ed) Weed physiology. Boca Raton, Florida: CRC, 1965. v. 1, p. 27-67.
GRANT LIPP, A.L.; BALLARD, I.A.T. The breaking of seed dormancy of some legumes by carbon dioxide. Australian Journal of Agriculture Research, v. 10, p. 495-499, 1959.

HOLM, R.E. Volatile metabolites controlling germination in buried weed seeds. Plant Physiology, v. 50, p. 293297, 1972.

HOROWITZ, M.; REGEV, Y.; GIVELBERG, A. A plastic mulch as a method of weed control. In: CONFERENCE OF THE WEED SCIENCE SOCIETY OF ISRAEL, 7, 1979. Abstracts. Apud Phytoparasitica, v. 7, n. 2, p. 142, 1979.

HOROWITZ, M.; REGEV, Y; HERZLINGER, G. Solarization for weed control. Weed Science, Champaign, v. 31, p. 170-179, 1983.

JACOBSOHN, R.; GRENBERGER, A.; KATAN, J.; LEVI, M.; ALON, H. Control of Egyptian broomrape (Orobanche aegypteiaca) and other weeds by means of solar heating of the soil by polyethylene mulching. Weed Science, Champaign, v. 28, p. 312-315, 1980.

KATAN, J. Solar heating (solarization) of soil for control of soilborne pests. Annual Review of Phytopathology, Palo Alto, v. 19, p. 211-236, 1981.

LIAKATAS, A.; CLARK, J.A.; MONTEITH, J.L. Meassurements of the heat balance under plastic mulches. Part 1. Radiation balance and soil heat flux. Agricultural Forestry Meteorology, Amsterdam, v. 36, n. 3, p. 227-239, 1986

MAGALHÃES, A.C. Influência do teor de umidade no tubérculo e da quantidade de água disponível no solo sobre a capacidade de brotação da tiririca. Bragantia, Campinas, v. 24, n. 37, p. 507-513,1965.

RUBIN, B.; BENJAMIN, A. Solar heating of the soil effects on weed control and soil-incorporated herbicides. Weed Science, Champaign, v. 31, p. 819-824, 1983.

RUBIN, B.; BENJAMIN, A. Solar heating of the soil: involvement of environmental factors on the weed control process. Weed Science, Champaign, v. 32, p. 138$142,1984$.

STANDIFER, L.C.; WILSON, P.W.; PORCHE-SORBET, R. Effects of solarization of soil weed seed popula tions. Weed Science, Champaign, v. 32, p. 569-573, 1984.

STIVENS, C.; KHAN, V.A.; OKORONKWO; TANG, A. G.; WILSON, M.A.; LU, J. Soil solarization and dacthal: Influence on weeds, growth, and root microflora of Collards. Horticultural Science,Calcutta, v. 25, n. 10, p. 1260-1262,1990.

TAYLORSON, R.B. Response of weed seeds to ethyle ne and related hydrocarbons. Weed Science, Champaign, v. 27, p. 7-10, 1979.

ZUNKER, E.; KREEB, K. Untersuchungen zur potentiometricschen Messung der photosyntheserate. Ber. Deutsch. Bot. Ges., v. 83, p. 245-57, 1970. 